\title{
A QUALIDADE DA ÁGUA DAS MINAS UTILIZADAS PARA FINS DE POTABILIDADE EM PONTOS DE AFLORAMENTOS DO AQUÍFERO BAURU NO ENTORNO DE PRESIDENTE PRUDENTE/SP
}

Naiara Alves Siste, Alexandre Teixeira de Souza

Engenharia Ambiental - UNOESTE. E-mail: naiara.adm.siste@hotmail.com

\section{RESUMO}

A região de Presidente Prudente situa-se sobre um aquífero de comportamento livre, aquífero Bauru, no qual uma das principais características é a fácil e rápida absorção de substâncias que se encontram no solo, assim como uma quantidade elevada de afloramentos. Muitos destes afloramentos situam-se nas rodovias e ruas das cidades da região, onde diariamente se pode observar a população coletando água de tais fontes para fins de potabilidade, sem conhecer a real qualidade para o fim mencionado, expondo-se a possibilidades de contaminação por fatores físicoquímicos e biológicos. Para verificar as condições de tais afloramentos, foram selecionados cinco pontos de coleta de água e posteriormente analisados em laboratório a partir dos seguintes parâmetros: coliformes totais, Escherichia coli,dureza total, ferro, nitrato, nitrito, $\mathrm{pH}$ e sólidos totais dissolvidos. Os resultados indicaram que todas as fontes estavam em desconformidade com relação ao parâmetro Escherichia coli, de acordo com a Resolução CONAMA no 396 de 2008, tornando-as inapropriadas ao consumo humano. Tais resultados expõem a atual necessidade de monitoramento, manutenção e recuperação das atuais fontes existentes.

Palavras-chave: fonte, contaminação, rodovias, potabilidade; aquífero Bauru.

\section{INTRODUÇÃO}

A região de Presidente Prudente situa-se sobre o aquífero sedimentar Bauru, que se estende por uma área de $96.900 \mathrm{~km}^{2}$, ocorrendo de Barretos a Bauru e chegando até o Pontal do Paranapanema. Tal aquífero é constituído por arenitos, arenitos argilosos e siltitos, com ou sem cimentação carbonática, apresenta espessura média saturada de $75 \mathrm{~m}$, atingindo entre 150 a 200m na região de São José do Rio Preto/SP e Presidente Prudente/SP, em certos pontos são averiguadas concentrações excessivas de crômio, nitrato e bário (CETESB, 2010).

No aquífero Bauru a água subterrânea encontra-se a pouca profundidade, em geral as águas deste aquífero possuem boa qualidade de potabilidade, porém existem poços onde foram detectadas concentrações de cromo e nitrato que ultrapassam padrões de potabilidade de água para consumo humano. Pela recarga ocorrer em toda sua extensão, já que se trata de um aquífero livre, o risco de poluição é maior, pois recebem recarga direta das águas que caem sobre o solo e infiltram em subsuperfície (IRITANI; EZAKI, 2008). Tal fato chama a atenção para a necessidade de um esforço conjunto do governo e da sociedade no desenvolvimento de programas e implantação de ações destinadas à sua proteção. 
A água é considerada potável quando não possui substâncias tóxicas e/ou microrganismos patogênicos que provocam doenças. Os padrões de potabilidade de água são os limites de tolerância das substâncias presentes na água, com o passar do tempo e a descoberta de novas formas de análises os padrões tornam-se mais rigorosos, os principais fatores analisados são os físico-químicos e microbiológicos.

Em 1979 o Departamento de Águas e Energia Elétrica publicou um estudo no qual menciona a qualidade das águas subterrâneas das regiões 10 e 11 do estado de São Paulo, respectivamente Presidente Prudente e Marília; com relação a potabilidade contatou-se alguns poucos pontos contaminados decorrente de má construção do poço e falta de proteção sanitária.

O relatório da qualidade das águas subterrâneas feito pela CETESB (1998), com relação ao triênio de 1994 a 1997, indicou que 15\% dos poços analisados no estado de São Paulo, principalmente os do aquífero Bauru (o qual se encontra a região de Presidente Prudente), apresentaram contaminação por nitrato, potássio, crômio total e parâmetros microbiológicos, no triênio seguinte a mesmo região apresentou um aumento da contaminação por nitrato e crômio.

Tanto o nitrito como o nitrato está associado a dois efeitos na saúde humana: "a indução à metemoglobinemia e a formação potencial de nitrosaminas e nitrosamidas carcinogênicas" (ALABURDA; NISHIHARA, 1998, Apud TOURINHO; BERETTA, 2010).

De acordo com o IPAS - Indicador de Potabilidade das Águas Subterrâneas, entre 2007 e 2009 os parâmetros em desconformidade no aquífero Bauru foram: Alumínio, bário, crômio, ferro, nitrato, coliformes totais e bactérias heterotróficas (CETESB, 2010).

Conforme relatório de Áreas Contaminadas e Reabilitadas no Estado de São Paulo da CETESB (2010), 33 áreas da região de Presidente Prudente foram contaminadas por atividades ligadas aos setores comercial e industrial ou por resíduos. Em Pirapozinho/SP o solo e subsolo foram contaminados por metais através de disposição, infiltração e tratamento de efluentes pela indústria Bracol Holding Ltda; também houve contaminação do subsolo por armazenamento de solventes aromáticos pelo Mônaco Auto Posto Ltda em Presidente Bernardes/SP o posto Kuroce \& Olivo Ltda foi responsabilizado pela contaminação do subsolo e águas subterrâneas. Em Presidente Prudente foram citados 15 estabelecimentos, sendo: 9 postos de combustíveis, comércio Crevron Brasil, Curtume Touro, Comércio Esso Brasileira de Petróleo, indústria Prolub Refino de Lubrificantes e uma área da prefeitura de Presidente Prudente contaminada por infiltração de resíduos na rua José Bongiovani, 975, onde se encontra o cemitério municipal. 
CETESB (2007) aponta outras cidades aos arredores de Presidente Prudente com empreendimentos poluidores do subsolo, dentre elas: Álvares Machado, Pirapozinho, Presidente Bernardes e Regente Feijó. Em $80 \%$ dos casos, a contaminação está relacionada com a armazenagem de materiais, o restante está ligado a descarte e disposição e resíduos ou infiltração.

Diante do exposto, percebe-se a importância da população ser informada da verdadeira qualidade de tais fontes, por uma questão cultural, a população acredita que a água proveniente de minas, por definição, tem uma qualidade potável garantida. É recorrente a observação de pessoas as margens de rodovias coletando água de fontes as quais não sabem se realmente são potáveis. As consequências da ingestão de água contaminada vão de um simples mal estar ao desenvolvimento de doenças graves.

\section{METODOLOGIA}

Para o desenvolvimento da pesquisa, inicialmente realizaram-se revisões bibliográficas e levantamentos de dados disponíveis necessários ao trabalho. Para avaliar a qualidade das águas das fontes do aquífero Bauru, em alguns pontos no entorno da região de Presidente Prudente/SP, utilizados como fonte de coleta de água para fins de ingestão pela população da região, foram analisados alguns parâmetros de potabilidade presentes na Resolução CONAMA no 396 de 2008. A localização dos pontos de coleta de água nos afloramentos, os quais havia considerável visita da população, estão ilustrados na Tabela 01. 
Tabela 01. Pontos de coleta para análise de água

\begin{tabular}{|c|c|c|}
\hline FONTE & CIDADE & LOCALIDADE \\
\hline 10 & Santo Anastácio & $\begin{array}{c}\text { Rodovia Raposo Tavares, } \\
\text { entre o Km597 leste e o } \\
\text { Km596 leste (lado } \\
\text { esquerdo). } \\
\text { Anexo } 1 \\
\end{array}$ \\
\hline 20 & Santo Anastácio & $\begin{array}{c}\text { Estrada proveniente da } \\
\text { Rua José Lutti - Vila } \\
\text { Ortega, a } 1 \text { km da Rodovia } \\
\text { Raposo Tavares } \\
\text { Anexo } 2\end{array}$ \\
\hline 30 & Álvares Machado & $\begin{array}{c}\text { Rodovia Raposo Tavares, } \\
\text { entre o Km573 leste e o } \\
\text { Km572 leste (lado } \\
\text { esquerdo) } \\
\text { Anexo } 3\end{array}$ \\
\hline 40 & Presidente Prudente & $\begin{array}{c}\text { Bairro Jardim Santa Fé, } \\
\text { Rua Pedro Karrer (rua } \\
\text { paralela a rodovia Julio } \\
\text { Budisk) } \\
\text { Anexo } 4\end{array}$ \\
\hline 50 & Presidente Prudente & $\begin{array}{c}\text { Rodovia Raposo Tavares, } \\
\text { entre o Km571 leste e o } \\
\text { Km570 leste (lado direito) } \\
\text { Anexo } 5\end{array}$ \\
\hline
\end{tabular}

As amostras foram coletadas em recipientes esterilizados e adequados a cada tipo de análise biológica e química. Após a coleta, as amostras foram levadas ao Laboratório de Análises de águas da Universidade do Oeste Paulista (UNOESTE), onde se realizaram as análises dos seguintes parâmetros: coliformes totais, Escherichia coli, dureza total, ferro, nitrato, nitrito, $\mathrm{pH}$ e sólidos totais dissolvidos.

\section{RESULTADOS}

A Tabela 02 demonstra os resultados dos parâmetros analisados experimentalmente em laboratório de cada ponto de amostragem e os valores máximos permitidos pela Resolução CONAMA 396 de 2008. 
Tabela 02.Resultado das análises dos parâmetros

\begin{tabular}{|c|c|c|c|c|c|c|c|c|}
\hline & \multicolumn{7}{|c|}{ Parâmetros - mg/L } \\
\hline Fontes & $\begin{array}{c}\text { Coliformes } \\
\text { totais }\end{array}$ & $\begin{array}{c}\text { Escherichia } \\
\text { coli }\end{array}$ & $\begin{array}{c}\text { Dureza } \\
\text { total }\end{array}$ & Ferro & Nitrato & Nitrito & $\mathrm{pH}$ & $\begin{array}{c}\text { Sólidos } \\
\text { totais } \\
\text { dissolvidos }\end{array}$ \\
\hline 1 & Ausência & Presença & 18,00 & $<0,03$ & 2,20 & 0,02 & 5,54 & 40,00 \\
\hline 2 & Presença & Presença & 20,00 & $<0,03$ & 2,40 & 0,02 & 5,73 & 41,96 \\
\hline 3 & Presença & Presença & 15,00 & 0,08 & 1,80 & 0,01 & 5,50 & 23,00 \\
\hline 4 & Presença & Presença & 48,00 & 0,15 & 6,90 & 0,03 & 5,50 & 32,00 \\
\hline 5 & Presença & Presença & 13,00 & 0,09 & 3,40 & 0,02 & 6,07 & 32,00 \\
\hline $\begin{array}{c}\text { Resolução } \\
\text { CONAMA } \\
\text { 396 }\end{array}$ & Ausência & Ausência & $\mathbf{1 0 0 , 0 0}$ & $\mathbf{0 , 3 0}$ & $\mathbf{1 0 , 0 0}$ & $\mathbf{1 , 0 0}$ & $\mathbf{7 , 5 0}$ & $\mathbf{1 0 0 0 , 0 0}$ \\
\hline
\end{tabular}

\section{DISCUSSÃO}

De acordo com os resultados, verifica-se que somente dois parâmetros estão em desconformidade com a legislação vigente: a Escherichia coli, encontrado em todas as amostras, e Coliformes Totais,encontrado em todas as fontes com exceção da primeira.Os parâmetros dureza total, ferro, nitrato, pH e sólidos totais dissolvidos, se encontram dentro dos padrões da resolução CONAMA no 396/08. O grupo coliforme está presente no intestino humano e de animais de sangue quente, porém nem todas as bactérias deste grupo são de origem fecal, podendo ser encontrada naturalmente no solo, na água e em plantas; em climas tropicais possuem a capacidade de se multiplicar na água. A presença de Escherichia coli é um importante indício de contaminação fecal, pois indica a contaminação de origem animal silvestre, que pode conter agentes patogênicos ao ser humano.

Todos os afloramentos analisados encontram-se em locais onde animais de pastagem e domésticos transitam, sendo os principais indicadores de contaminação, já que os afloramentos são de lençóis superficiais facilmente contamináveis por atividades no solo.Sendo assim, não é indicado o consumo de água em tais afloramentos.

Em situações onde tal consumo é inevitável existem técnicas de descontaminação bacteriológicas alternativas, como por exemplo: em dias de céu sem nuvens ou parcialmente nublado pode-se deixar a garrafa pet (de origem conhecida e bem limpa) com a água coletada exposta ao sol por cerca de 6 horas, em dias nublados indica-se que a exposição seja de 48 horas. A fervura da água é a indicação mais rápida e efetiva para desinfecção das desconformidades encontradas. Por desconhecimento da real situação de inúmeros parâmetros para assegurar a 
potabilidade de tais afloramentos, é recomendável a não utilização destas fontes para nenhuma finalidade de uso humano.

\section{CONCLUSÃO}

Os resultados indicaram que todas as fontes estavam fora dos padrões microbiológicos de potabilidade para água de consumo humano em relação ao parâmetro Escherichia coli, de acordo com a Resolução CONAMA no 396 de 2008, tornando-as inapropriadas ao consumo humano. Devido à superficialidade de tais lençóis, o risco de contaminação dessas águas se torna elevado. Os resultados demonstram a susceptibilidade à contaminação desse tipo de fonte, principalmente no período de chuva, em decorrência da percolação rápida dos microrganismos em direção à água subterrânea, pois todas as fontes analisadas estavam expostas a contaminação biológica proveniente de animais, como gado, porcos, cavalos e animais domésticos em geral. Tais resultados expõem a atual necessidade de conscientização da população a respeito dos riscos envolvidos no consumo de fontes com qualidade desconhecida. A adoção de medidas preventivas, visando à preservação das fontes de água, são as ferramentas necessárias para diminuir consideravelmente o risco de ocorrência de enfermidades de veiculação hídrica.

\section{REFERÊNCIAS}

AESABESP. Novos padrões de potabilidade da água para consumo humano. S.D. AESABESP. Disponível em: <http://www.aesabesp.org.br/projetos-socioambientais/carteiras/783-novospadroes-de-potabilidade-da-agua-para-consumo-humano.html>. Acesso em: 30 de abr de 2012.

CETESB. Companhia de Tecnologia de Saneamento Ambiental. Relatório de qualidade das águas subterrâneas do estado de São Paulo: 2007-2009. São Paulo: CETESB, 2010. 258 p.

CETESB. Companhia de Tecnologia de Saneamento Ambiental. Coleta e Preservação de Amostras de Água: 1988. 160p.

CUNHA, A.C. Monitoramento, Parâmetros e Controle da Qualidade da Água - curso para engenheiros e técnicos das Unidades de Monitoramento (OEMAs). Macapá, 2000.

Departamento de Águas e Energia Elétrica. Diretoria de Planejamento e Controle. Divisão de Planejamento e Recursos Hídricos. Estudo de Águas subterrâneas das regiões administrativas 10 e 11 - Presidente Prudente e Marília. São Paulo, 1979. 220p.

IRITANI, Mara Akie; EZAKI, Sibele. As águas subterrâneas do Estado de São Paulo. - São Paulo: Secretaria de Estado do Meio Ambiente - SMA, 2008. 104p. 
MESSIAS, Arminda Saconi; COSTA, Marcos Roberto Nunes. Água subterrânea e dessalinização Recife: UNICAP, 2006. 200p. Série encontro das águas, n.2.

MINISTÉRIO DA SAÚDE. Boas práticas no abastecimento de água: Procedimentos para a minimização de risco a saúde. Secretária de vigilância em saúde - Brasília, 2006. 252p

RESOLUÇÃO CONAMA n ${ }^{\circ}$ 396, de 3 de abril de 2008, Publicada no DOU no 66, de 7 de abril de 2008, Seção 1, páginas 64-68.

TOURINHO, Aucimaia de Oliveira; BERETTA, Magda. Presença de nitrato nas águas de fontes naturais da cidade de Salvador, Bahia. I Congresso Baiano de Engenharia Sanitária e Ambiental COBESA. 2010. 19p.

TUNDISI, José Galizia. Água no século XXI: Enfrentando a escassez - São Carlos: RiMa, IIE, 2. ed., 2005. 248p.

Anexo

Fotos dos afloramentos

Anexo 1:

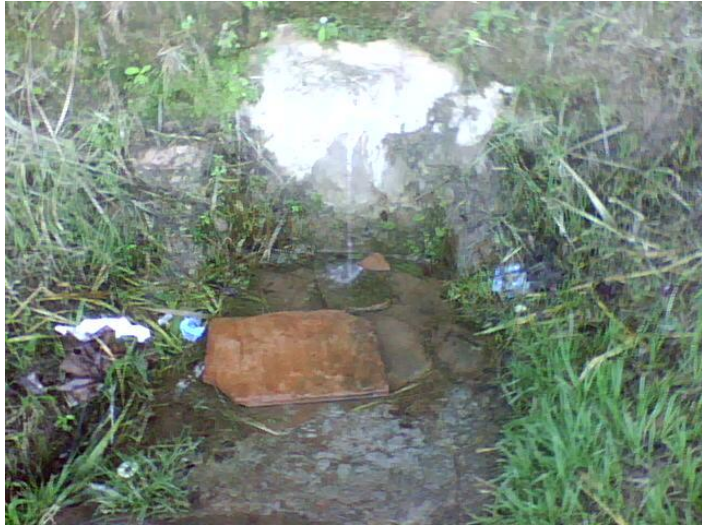

\section{Anexo3}

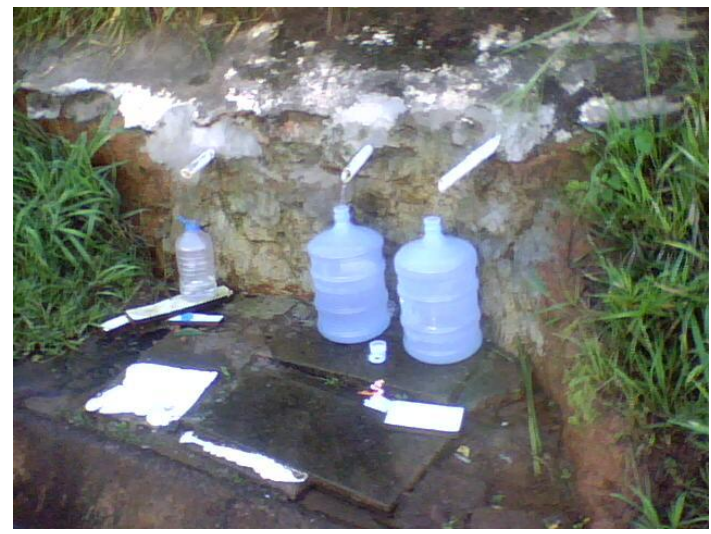

Anexo 2

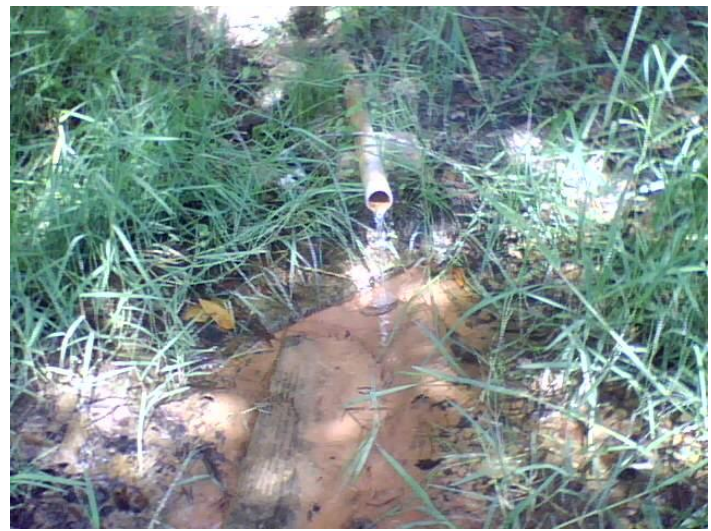

\section{Anexo 4}

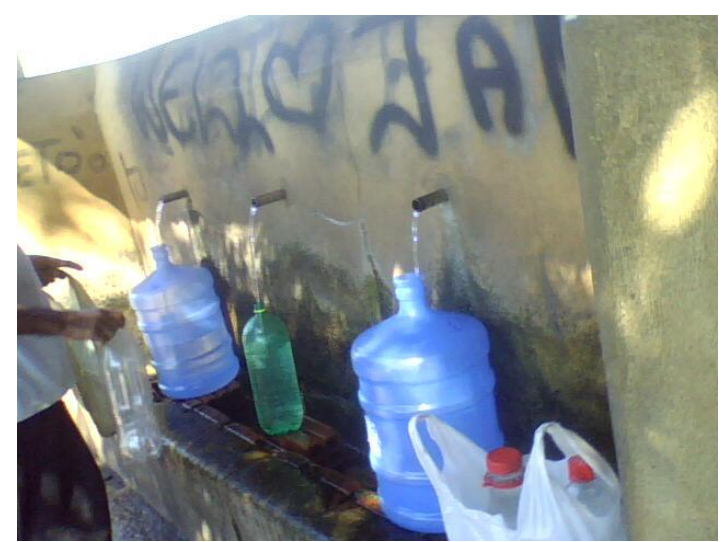




\section{Anexo 5}

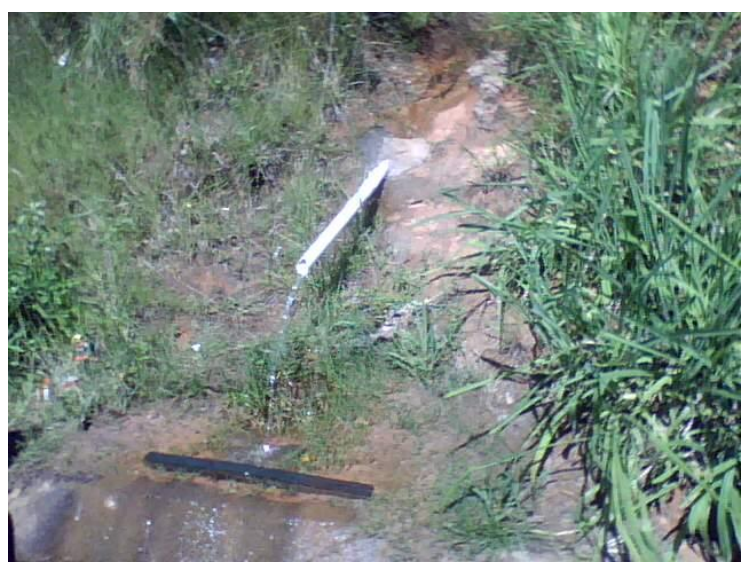

